PAPER

\title{
Gamma knife treatment for refractory cluster headache: prospective open trial
}

\section{A Donnet, D Valade, J Régis}

See end of article for authors' affiliations

.....................

Correspondence to: Dr A Donnet, Service de Neurochirurgie, Hôpital la Timone, 264 bd Saint Pierre, 13385 Marseille Cedex 05, France: adonne†@AP-HM.fr

Received 8 March 2004 In revised form 19 April 2004 Accepted 25 May 2004
Background: Since the initial report of Ford et al in 1998 no further study has evaluated radiosurgery of the trigeminal nerve in chronic cluster headache $(\mathrm{CCH})$.

Methods: We carried out a prospective open trial of neurosurgery and enrolled 10 patients (nine men, one woman; mean age 49.8 years, range $32-77$ ) presenting with severe and drug resistant $\mathrm{CCH}$ (mean duration 9 years, range 2-33). The cisternal segment of the nerve was targeted with a single $4 \mathrm{~mm}$ collimator (80-85 Gy max).

Results: The mean follow up was 13.2 months. No improvement was observed in two patients and three patients had no further attacks. Three patients showed dramatic improvement with a few attacks per month or very few attacks over the last six months. Two patients were pain free for only one and two weeks and their headaches recurred with the same severity as before. Three patients developed paraesthesia with no hypoaesthesia, one developed hypoaesthesia, and one developed deafferentation pain.

Conclusions: The rate and severity of trigeminal nerve injury appeared to be significantly higher than in trigeminal neuralgia, and this study does not support the positive results of the study of Ford et al. We consider the morbidity to be significant for the low rate of pain cessation, making this procedure less attractive even for the more severely affected subgroup of patients.
$\mathrm{C}$ uster headache is one of the most debilitating headache syndromes. It is characterised by attacks of strictly unilateral, severe pain in an orbital, supraorbital, or temporal location. The attacks last 15-180 minutes and usually occur once or several times per day, especially at night, accompanied by ipsilateral conjunctival injection, lacrimation, rhinorrhoea, or nasal congestion and agitation. ${ }^{1}$

About $90 \%$ of people with cluster headache have the episodic form, but $10 \%$ have chronic cluster headache $(\mathrm{CCH})$ in which the attacks are closely spaced with periods of remission lasting no longer than 30 days or pain without remission for more than a year. Once the chronic cluster syndrome is established, medical treatment is of limited success. ${ }^{2}$ Hence, it is not surprising that various invasive and surgical procedures have been attempted in the hope of providing symptomatic relief. The clinical criteria for surgery in $\mathrm{CCH}$ are: total resistance to pharmacotherapy, headache "locked" to the same side; pain mainly in the region of the ophthalmic division of the trigeminal nerve; and psychologically stable individuals. The response to previous sphenopalatine ganglion blockade is not considered sufficiently specific to serve as an inclusion/exclusion criterion. ${ }^{3}$

Surgery has been carried out at many sites in an attempt to cure cluster headache $e^{4}$ interruption of the parasympathetic pathways by sectioning the intermedius nerve, ${ }^{5}$ the greater superficial petrosal nerve, or the sphenopalatine ganglion, ${ }^{6}$ or by lesioning of the trigeminal nerve. ${ }^{7-9}$ In 1998, Ford et al reported positive results after radiosurgical targeting of the trigeminal nerve. ${ }^{10}$ Since this initial report no other attempts have been made to evaluate trigeminal nerve radiosurgery in $\mathrm{CCH}$ and no long term follow up study has been published by Ford's team.

We organised a multicentre, prospective, self-controlled trial to evaluate strictly the safety and efficacy of gamma knife treatment (trigeminal nerve radiosurgery) in $\mathrm{CCH}$. Here we report the preliminary results of the treatment.

\section{PATIENTS AND METHOD}

We carried out a multicentre (Marseille and Paris), prospective, non-blinded open trial of radiosurgery without clinical controls. Between January 2002 and February 2003, 10 patients (nine men, one woman) presenting with very severe and drug resistant $\mathrm{CCH}$ were enrolled. The candidates for gamma knife surgery were selected according to the following criteria: $(a)$ the patient met the criteria of $\mathrm{CCH}$ as defined by the International Headache Society classification and $(b)$ failure of appropriate drug treatment including verapamil (480-1200 mg per day) and lithium. Medical treatment was perceived to have failed on the basis that the physician administered optimal medications at high therapeutic serum concentrations. Previous prophylactic treatments are summarised in table 1 . At the time of this data collection, the role of antiepileptic drugs in the treatment of $\mathrm{CCH}$ was not clearly defined. However, there are no established guidelines for medically intractable $\mathrm{CCH}$.

The protocol of the prospective trial was submitted to the ethics committee and to the health authorities and modified according to their recommendations. An information brochure and explanation of the procedure was given to the patient and informed consent obtained. This was signed by the patient and the investigator. The experimental nature of the procedure was extensively explained. The specific risk of failure or side effects and especially the risk of hypoaesthesia and deafferentation pain was explained to the patients.

The patients were admitted to the Marseille Timone University Hospital the day before radiosurgery and discharged the day after (two nights). The frame was applied under local anaesthesia after administration of mild sedative medication. The frame was placed so that the base ring of the frame was parallel to the trigeminal nerve axis. ${ }^{11}$

Preoperative stereotactic imaging systematically included magnetic resonance (MR) and computed tomography (CT)

Abbreviation: $\mathrm{CCH}$, chronic cluster headache 


\begin{tabular}{|c|c|c|c|c|c|c|}
\hline Patient & Age & Sex & $\begin{array}{l}\text { Chronic } \\
\text { since }\end{array}$ & $\begin{array}{l}\text { No. of } \\
\text { aftacks/day }\end{array}$ & Failed previous prophylactic treatment & $\begin{array}{l}\text { Date of gamma } \\
\text { knife surgery }\end{array}$ \\
\hline 1 & 47 & M & 1985 & 1 & $\begin{array}{l}\text { Verapamil }(840 \mathrm{mg} / \mathrm{d}) ; \text { clomipramine }(125 \mathrm{mg} / \mathrm{d}) ; \text { amitriptyline }(100 \mathrm{mg} / \mathrm{d}) ; \\
\text { gabapentin }(3600 \mathrm{mg} / \mathrm{d}) ; \text { valproate }(1 \mathrm{~g} / \mathrm{d}) ; \text { indometacin }(150 \mathrm{mg} / \mathrm{d}) ; \mathrm{methysergide}(4.95 \mathrm{mg} / \mathrm{d}) ; \\
\text { propranolol }(80 \mathrm{mg} / \mathrm{d}) \text {; lithium }(750 \mathrm{mg} / \mathrm{d}) \text {; baclofen }(75 \mathrm{mg} / \mathrm{d})\end{array}$ & 02/01/02 \\
\hline 2 & 52 & M & 1992 & $5-6$ & $\begin{array}{l}\text { Verapamil }(720 \mathrm{mg} / \mathrm{d}) \text {; lithium }(750 \mathrm{mg} / \mathrm{d}) \text {; methysergide }(4.95 \mathrm{mg} / \mathrm{d}) \text {; indometacin }(200 \mathrm{mg} / \mathrm{d}) \text {; } \\
\text { propranolol }(120 \mathrm{mg} / \mathrm{d}) \text {; two occipital nerve blockades: } 1996 \text { and } 1999\end{array}$ & $05 / 02 / 02$ \\
\hline 3 & 60 & M & 2000 & 2 & $\begin{array}{l}\text { Verapamil }(720 \mathrm{mg} / \mathrm{d}) \text {; lithium }(750 \mathrm{mg} / \mathrm{d}) \text {; methysergide }(4.95 \mathrm{mg} / \mathrm{d}) \text {; indometacin }(200 \mathrm{mg} / \mathrm{d}) \text {; } \\
\text { propranolol }(160 \mathrm{mg} / \mathrm{d}) \text {; two occipital nerve blockades: } 2001 \text { and } 2002\end{array}$ & 06/06/02 \\
\hline 4 & 43 & M & 2000 & 1 & $\begin{array}{l}\text { Verapamil }(600 \mathrm{mg} / \mathrm{d}) \text {; lithium }(750 \mathrm{mg} / \mathrm{d}) \text {; amitriptyline }(100 \mathrm{mg} / \mathrm{d}) \text {; } \\
\text { clomipramine }(75 \mathrm{mg} / \mathrm{d}) \text {; valproate }(1 \mathrm{~g} / \mathrm{d} \text {; successful but pancreatitis); topiramate }(100 \mathrm{mg} / \mathrm{d} \text {; } \\
\text { adverse effects ++); gabapentin }(1.2 \mathrm{~g} / \mathrm{d})\end{array}$ & $27 / 06 / 02$ \\
\hline 5 & 35 & M & 2000 & 1 & Verapamil $(720 \mathrm{mg} / \mathrm{d})$; lithium $(750 \mathrm{mg} / \mathrm{d})$; methysergide $(4.95 \mathrm{mg} / \mathrm{d})$; indometacin $(200 \mathrm{mg} / \mathrm{d})$ & 05/07/02 \\
\hline 6 & 62 & M & 2002 & 3 & Verapamil $(960 \mathrm{mg} / \mathrm{d})$; lithium $(750 \mathrm{mg} / \mathrm{d})$; methysergide $(4.95 \mathrm{mg} / \mathrm{d})$; indometacin $(200 \mathrm{mg} / \mathrm{d})$ & $17 / 10 / 02$ \\
\hline 7 & 50 & M & 1998 & 2 & $\begin{array}{l}\text { Verapamil }(720 \mathrm{mg} / \mathrm{d}) \text {; lithium }(750 \mathrm{mg} / \mathrm{d}) \text {; valproate }(1.5 \mathrm{~g} / \mathrm{d}) \text {; indometacin }(200 \mathrm{mg} / \mathrm{d}) \text {; } \\
\text { propranolol }(160 \mathrm{mg} / \mathrm{d})\end{array}$ & 05/11/02 \\
\hline 8 & 77 & $\mathrm{~F}$ & 1970 & 1 & $\begin{array}{l}\text { Verapamil }(960 \mathrm{mg} / \mathrm{d}) \text {; lithium }(750 \mathrm{mg} / \mathrm{d}) \text {; topiramate }(150 \mathrm{mg} / \mathrm{d}) \text {; methysergide }(4.95 \mathrm{mg} / \mathrm{d}) \text {; } \\
\text { indometacin }(200 \mathrm{mg} / \mathrm{d})\end{array}$ & $21 / 01 / 03$ \\
\hline 9 & 32 & M & 2000 & 6 & Verapamil $(720 \mathrm{mg} / \mathrm{d})$; lithium $(750 \mathrm{mg} / \mathrm{d})$; valproate $(1.5 \mathrm{~g} / \mathrm{d})$; occipital nerve blockade: 2001 & 18/02/03 \\
\hline 10 & 40 & M & 1995 & 5 & $\begin{array}{l}\text { Verapamil }(720 \mathrm{mg} / \mathrm{d}) \text {; lithium }(750 \mathrm{mg} / \mathrm{d}) \text {; methysergide }(4.95 \mathrm{mg} / \mathrm{d}) \text {; indometacin }(200 \mathrm{mg} / \mathrm{d}) \text {; } \\
\text { two occipital nerve blockades: } 1999 \text { and } 2000\end{array}$ & $25 / 02 / 03$ \\
\hline
\end{tabular}

scans. The MR (Siemens 1.5 Tesla) sequences included a T2 high resolution $(0.5 \mathrm{~mm})$ three dimensional acquisition (CISS; constructive interference study state sequence from Siemens) acquired in the axial plan and a three dimensional Tl acquisition (MPR) $1.5 \mathrm{~mm}$ thick. CT scan bone window acquisition served as part of the quality control to check and eventually correct the distortion of the MR images. ${ }^{10}$ The cisternal segment of the nerve (defined as the part between Meckel's cave and the pons) was targeted with a single $4 \mathrm{~mm}$ collimator. The target used in this study was exactly the same as the one we are using for essential trigeminal neuralgiathe anterior aspect of the cisternal segment of the nerve partially overlapping the plexus triangularis. ${ }^{12}$ The target was set as anteriorly as possible in the cistern to cover the plexus triangularis and to decrease the energy delivered to the brainstem. The maximum dose $(100 \%)$ as defined in the protocol was $80-85 \mathrm{~Gy}$. It was $80 \mathrm{~Gy}$ in nine patients and $85 \mathrm{~Gy}$ in one patient. A model C gamma knife (Elekta AB, Stockholm) was used for the radiosurgical procedure.

\section{RESULTS}

The mean age of the 10 patients was 49.8 years (range $32-77$ ) and mean duration of the cluster headache was 9 years (range 2-33). The patients were followed up for a mean of 13.2 months (range 8-21) and evaluated at 3, 6, and 12 months. For evaluation of the treatment results, the patients were divided into four categories: excellent, good, fair, and failure. The result was considered to be excellent if the patient was free of cluster headache and took minimal or no medication, and good if the cluster headache reduced in severity and frequency by $50 \%$ and prophylactic medications were continued. Fair results indicated improvement of $25 \%$ or less, with continued use of prophylactic treatment. Patients with no relief at all were considered failures. The results at one year are detailed in table 2 .

Three patients had complete relief from CCH (patients 3, 9, and 10), of whom one (patient 9) was on prophylactic treatment during follow up; patients 9 and 10 had the shortest follow up and the experience of other surgical methods demonstrated that an initial response can be obtained followed by recurrence. Patient 3 had no further medical treatment. This patient underwent greater occipital nerve blockade on day 37 with complete cessation of pain. He had been treated before with this technique but had never had such a long remission-in this case, it is difficult to state which technique led to complete relief.
Three patients showed dramatic improvement with a few attacks per month or very few attacks over the last six months (patients 2, 5, and 6). We considered their results good, and they continued to use preventive medications. Three patients had immediate relief of $\mathrm{CCH}$ or were free of attacks within a week following gamma knife surgery. There is no explanation for this and was also reported by Ford et al. ${ }^{10}$

Two patients were pain free for only one and two weeks and had recurrence of cluster headache with the same severity and frequency as before (patients 1 and 4). No improvement was observed in two patients (failures; patients 7 and 8 ).

No patient sustained an immediate complication after the gamma knife procedure. Three patients developed paraesthesia with no hypoaesthesia, one developed hypoaesthesia, and one developed deafferentation pain. The severity of the deafferentation pain in this last patient (patient 1) led us to perform a cortical stimulation.

\section{DISCUSSION}

Chronic cluster headache is the most severe primary headache syndrome known. Improvement has been reported with surgical procedures classically proposed for trigeminal neuralgia, ${ }^{2}$ although with a low rate of pain cessation and a high rate of nerve damage. The pain and attacks of cluster headache might originate in or are mediated to a number of different sites: the regional orbital, internal or external carotid circulation, the cavernous sinus, the trigeminal vascular nervous connections, the sympathetic and parasympathetic nerves, and the hypothalamic centres (for review see references 13,14 ).

The exact aetiology and pathophysiology of cluster headache is yet to be fully elucidated. However, this syndrome has three major features: trigeminal distribution of the pain, accompanying ipsilateral symptoms of autonomic dysfunction, and episodic pattern of the attacks. First, the cluster headache pain is localised to the distribution area of the ophthalmic division of the trigeminal nerve, with the maximum pain invariably centred in or around the eye or forehead. The pain threshold is reduced within this area during the cluster headache periods. It is logical to assume that facial pain must reach the central nervous system through the trigeminal sensory nerve fibres and that, just as in trigeminal neuralgia, interruption of some part of the trigeminal system may prevent the painful impulses reaching the pons. Secondly, the ipsilateral autonomic features reflect parasympathetic dysfunction. The parasympathetic fibres arise from 
Table 2 Characteristics of the chronic cluster headache in ten patients following gamma knife surgery and follow up at one year

\begin{tabular}{|c|c|c|}
\hline Patient & Evolution of the chronic cluster headache and follow up & $\begin{array}{l}\text { Evaluation of treatment at } \\
\text { one year/side effects }\end{array}$ \\
\hline 1 & $\begin{array}{l}\text { Completely disappeared for first } 15 \text { days } \\
\text { Initially pain attacks less frequent } \\
21 \text { months follow up: pain as severe as before (1 attack/day) with prophylactic treatment } \\
\text { (verapamil } 600 \mathrm{mg} / \mathrm{d} \text {; clomipramine } 150 \mathrm{mg} / \mathrm{d} \text { ) }\end{array}$ & $\begin{array}{l}\text { Failure/hypoaesthesia } \\
\text { Deafferentation pain++ }\end{array}$ \\
\hline 2 & $\begin{array}{l}\text { June 2002: complete pain cessation } \\
20 \text { months follow up: } 1 \text { attack/month with prophylactic treatment (propranolol } 160 \mathrm{mg} / \mathrm{d} \text { ) }\end{array}$ & Good/0 \\
\hline 3 & $\begin{array}{l}\text { Until day } 7 \text { no pain } \\
\text { Day } 7 \text { to } 11: 2 \text { attacks/day } \\
\text { Day } 37: \text { greater occipital nerve blockade } \\
15 \text { months follow up: complete pain cessation; no prophylactic treatment }\end{array}$ & $\begin{array}{l}\text { Excellent/paraesthesia } \\
15 / 08 / 02 \text { no hypoaesthesia }\end{array}$ \\
\hline 4 & $\begin{array}{l}\text { Reduction in the frequency and severity of the pain attacks and complete stop at } 1 \text { week } \\
\text { December 2002: return of pain as before } \\
15 \text { months follow up: prophylactic treatment (verapamil } 480 \mathrm{mg} / \mathrm{d} \text { ) }\end{array}$ & Failure/0 \\
\hline 5 & $\begin{array}{l}\text { Transient improvement at } 5 \text { months } \\
13 \text { months follow up: } 4 \text { attacks } / \text { month with prophylactic treatment (verapamil } 480 \mathrm{mg} / \mathrm{d} \text { ) }\end{array}$ & $\begin{array}{l}\text { Good/paraesthesia without } \\
\text { hypoaesthesia }\end{array}$ \\
\hline 6 & $\begin{array}{l}\text { Complete disappearance of the pain at } 5 \text { months } \\
12 \text { months follow up: } 2 \text { attacks at } 6 \text { months; prophylactic treatment (verapamil } 360 \mathrm{mg} / \mathrm{d} \text { ) }\end{array}$ & $\begin{array}{l}\text { Good/hypoaesthesia } \\
\text { No corneal reflex }\end{array}$ \\
\hline 7 & No improvement at 11 months (verapamil $480 \mathrm{mg} / \mathrm{d}$; lithium $250 \mathrm{mg} / \mathrm{d}$ ) & Failure/paraesthesia (cheek) \\
\hline 8 & No improvement at 9 months & Failure/0 \\
\hline 9 & $\begin{array}{l}\text { No attacks in the last } 6 \text { months with treatment } \\
8 \text { months follow up: lithium } 750 \mathrm{mg} / \mathrm{d} \text {; valproate } 2 \mathrm{~g} / \mathrm{d}\end{array}$ & Excellent/0 \\
\hline 10 & 8 months follow up: no attack; no prophylactic treatment & Excellent/0 \\
\hline
\end{tabular}

the superior salivatory nucleus, exit the brain stem via the nervus intermedius and may also run in the seventh or eighth cranial nerves. ${ }^{2}$ Finally, the episodic and often time related consistency and seasonal predilection of attacks bears the signature of a dysfunctional central pacemaker which may be situated in the hypothalamus. In fact procedures targeting the trigeminal pathway have been employed, alcohol injection in the gasserian ganglion, root section of the trigeminal nerve, ${ }^{8} 1516$ glycerol rhizotomy, ${ }^{3}$ radiofrequency (RF) rhizolysis of the trigeminal nerve, ${ }^{7}$ and microvascular decompression of the trigeminal nerve or the nervus intermedius. ${ }^{17}$

Gamma knife radiosurgery is now a part of the available armamentarium for surgical therapy of essential trigeminal neuralgia. More recently this technique has been used in $\mathrm{CCH}^{10}$ targeting the trigeminal root entry zone in the pons. In this series, four men and two women with refractory $\mathrm{CCH}$ were treated with a dose of $70 \mathrm{~Gy}$ to the isocentre. Four of the six patients experienced excellent relief (defined as free from cluster headaches with minimal or no medication). One patient had good relief and the final patient's result was judged to be fair. No serious side effects were reported, however, the long term benefits were not evaluated in this study.

Among the proposed neurosurgical techniques, thermocoagulation of the trigeminal nerve or of the sphenopalatine ganglion and microvascular decompression have recently been re-evaluated. In 1997, Sanders and Zuurmond reported a series of 66 patients with refractory cluster headache treated with sphenopalatine ganglion blockade. Of these only 10 had CCH (and 56 episodic) ${ }^{3}$ and complete pain relief was obtained in three of these patients (partial relief in three). In 1995, Taha and Tew reported a series of seven patients with refractory $\mathrm{CCH}$ treated with $\mathrm{RF}$ rhizotomy. ${ }^{7}$ All the patients were reported to be pain free immediately after the procedure but at last follow up (median follow up five years; range 2-20 years) only two were still pain free (at seven and 20 years), and three had mild recurrence with good drug sensitivity. These authors reported one patient with complications (transient diplopia and keratitis). Two other series of patients who underwent trigeminal nerve root section confirmed that this procedure is an effective treatment with acceptable morbidity. ${ }^{15}{ }^{16}$ Finally, Lovely et al ${ }^{2}$ reported a series of 20 patients with $\mathrm{CCH}$ who underwent microvascular decompression of the trigeminal nerve alone $(n=9)$, or with microvascular decompression of the nervus intermedius $(n=3)$, or with sectioning of the nervus intermedius $(n=10)$. At the last follow up more than $90 \%$ reduction in pain was achieved in $45 \%$ of patients (nine patients) and more than $50 \%$ reduction in pain in six patients. Complications included one infected cranioplasty requiring removal, one cerebrospinal fluid leakage requiring spinal drainage, seven patients with headache requiring a lumbar puncture, but no hearing loss or facial palsy was reported.

Our experience with radiosurgery does not compare very favourably with the results of these series. However, due to the frequency of recurrences, irrespective of the technique used, other options should not be neglected. In our study of gamma knife surgery for trigeminal neuralgia (276 procedures) in spite of the use of the same target and a similar dose, hypoaesthesia remained rare $(\mathrm{n}=16 ; 5.8 \%)$, and we did not encounter severe hypoaesthesia associated with iatrogenic deafferentation pain (data under publication). Several hypotheses may be advanced to explain this intriguing discrepancy. Perhaps in patients with trigeminal neuralgia and structural alteration in the fifth cranial nerves this nerve is more resistant to radiosurgery. An alternative hypothesis may be an abnormal sensitivity of the nerve in CCH.

The rather high morbidity and low efficacy of radiosurgery directed towards the trigeminal nerve (at least in our hands) indicate that new therapeutic options should be explored. The first published results of posterior hypothalamic stimulation are encouraging. ${ }^{18} 19$ A few authors have proposed directing radiosurgery towards the sphenopalatine ganglion or both the sphenopalatine ganglion ${ }^{20}$ and the trigeminal nerve (Delotbinière, personal communication).

\section{CONCLUSION}

This first prospective evaluation of gamma knife surgery for cluster headache showed that complete pain cessation can be obtained over a significant period of time. However, long term evaluation is necessary. Our study does not support the positive results of the study of Ford et al. ${ }^{10}$ The rate and severity of trigeminal nerve injury appear to be significantly higher than in trigeminal neuralgia. ${ }^{21}$ We consider the 
morbidity to be significant for a low rate of pain cessation making this procedure less attractive even for the more severely affected subgroup of patients. Our group is evaluating other approaches. Moreover, we propose that recommendations for the criteria of medically intractable cluster headache, such as those developed for medically intractable epilepsy, are necessary. The role of the new antiepileptic drugs, in particular topiramate, ${ }^{22}$ in $\mathrm{CCH}$ has to be clarified.

\section{Authors' affiliations}

A Donnet, Service de Neurochirurgie, Hôpital la Timone, Marseille, France

D Valade, Centre d'Urgence Céphalée, Hôpital Lariboisière, Paris, France

J Régis, Service de Neurochirurgie Fonctionnelle and Stéréotaxique, Hôpital la Timone, Marseille, France

Competing interests: none declared

\section{REFERENCES}

1 International Classification of Headache Disorders, 2nd edn., Headache Classification Subcomittee of the IHS. Cephalalgia 2004;24(supp 1):1-160.

2 Lovely TJ, Kotsiakis X, Jannetta PJ. The surgical management of chronic cluster headache. Headache 1998;38:590-4.

3 Sanders M, Zuurmond WW. Efficacy of sphenopalatine ganglion blockade in 66 patients suffering from cluster headache: a 12- to 70-month follow-up evaluation. J Neurosurg 1997;87:876-80.

4 Rozen TD. Interventional treatment for cluster headache: a review of the options. Curr Pain Headache Rep 2002;6:57-64

5 Rowed DW. Chronic cluster headache managed by nervus intermedius section. Headache 1990;30:401-6.
6 Meyer JS, Binns PM, Ericsson AD, et al. Sphenopalatine gangionectomy for cluster headache. Arch Otolaryngol 1970;92:475-84.

7 Taha JM, Tew JM Jr. Long-term results of radiofrequency rhizotomy in the treatment of cluster headache. Headache 1995;35:193-6.

8 Matharu MS, Goadsby PJ. Persistence of attacks of cluster headache after trigeminal nerve root section. Brain 2002;125(Pt 5):976-84.

9 Green MW. Long-term follow-up of chronic cluster headache treated surgically with trigeminal tractotomy. Headache 2003;43:479-81.

10 Ford RG, Ford KT, Swaid S, et al. Gamma knife treatment of refractory cluster headache. Headache 1998:38:3-9.

11 Regis J, Bartolomei F, Metellus $\mathrm{P}$, et al. Radiosurgery for trigeminal neuralgia and epilepsy. Neurosurg Clin North Am 1999;10:359-77.

12 Regis J. High-dose trigeminal neuralgia radiosurgery associated with increased risk of trigeminal nerve dysfunction. Neurosurgery 2002;50:1401-2; author's reply 1402-3.

13 Schoenen J. Cluster headaches - central or peripheral in origin? Lancet 1998;352:253-5.

14 Goadsby PJ. Pathophysiology of cluster headache: a trigeminal autonomic cephalgia. Lancet Neurol 2002;1:251-7.

15 Kirkpatrick PJ, O'Brien MD, MacCabe JJ. Trigeminal nerve section for chronic migrainous neuralgia. $\mathrm{Br} J$ Neurosurg 1993;7:483-90.

16 Jarrar RG, Black DF, Dodlick DW, et al. Outcome of trigeminal nerve section in the treatment of chronic cluster headache. Neurology 2003;60:1360-2.

17 Solomon S, Apfelbaum RI. Surgical decompression of the facial nerve in the treatment of chronic cluster headache. Arch Neurol 1986;43:479-82.

18 Franzini A, Ferroli P, Leone M, et al. Stimulation of the posterior hypothalamus for treatment of chronic intractable cluster headaches: first reported series. Neurosurgery 2003;52:1095-9; discussion 1099-101.

19 Leone M, Franzini A, Broggi G, et al. Hypothalamic deep brain stimulation for intractable chronic cluster headache: a 3-year follow-up. Neurol Sci 2003;24(suppl 2):S143-S145.

20 Pollock BE, Kondziolka D. Stereotactic radiosurgical treatment of sphenopalatine neuralgia. Case report. J Neurosurg 1997:87:450-3.

21 Goss BW, Frighetto L, DeSalles AA, et al. Linear accelerator radiosurgery using 90 gray for essential trigeminal neuralgia: results and dose volume histogram analysis. Neurosurgery 2003;53:823-30.

22 Lainez MJ, Pascual J, Pascual AM, et al. Topiramate in the prophylactic treatment of cluster headache. Headache 2003;43:784-9. 